Article

\title{
Enhancement of Chlorophyll a Production from Marine Spirulina maxima by an Optimized Ultrasonic Extraction Process
}

\author{
Woon Yong Choi ${ }^{1}$ and Hyeon Yong Lee ${ }^{2, *}$ \\ 1 Department of Medical Biomaterials Engineering, Kangwon National University, Chuncheon 200-701, Korea; \\ cwy1012@hanmail.net \\ 2 Department of Food Science and Engineering, Seowon University, Cheongju 361-742, Korea \\ * Correspondence: hyeonl@seowon.ac.kr; Tel.: +82-43-299-8471
}

Received: 2 November 2017; Accepted: 20 December 2017; Published: 25 December 2017

\begin{abstract}
Under the optimal ultrasonification extraction conditions of $20.52 \mathrm{kHz}$ for the frequency, $32.59{ }^{\circ} \mathrm{C}$ for the temperature, and $4.91 \mathrm{~h}$ for the process time, $17.98 \mathrm{mg} / \mathrm{g}$ of chlorophyll a was obtained. It was much higher than $13.81 \mathrm{mg} / \mathrm{g}$ from conventional $70 \%$ ethanol extraction and even higher than other data from Spirulina. This yield was close to the predicted value of $18.21 \mathrm{mg} / \mathrm{g}$ from the second-order polynomial model with a regression coefficient of 0.969 . This model showed the greatest significance with the ultrasonic frequency and process time and the least significance with the temperature. The extracts also showed high $\alpha, \alpha$-diphenyl- $\beta$-picrylhydrazyl (DPPH) radical scavenging activities as $69.38 \%$, compared to $58.25 \%$ for the extracts from the $70 \%$ ethanol extraction. It was first shown that the optimal extraction was effective at enhancing the neuroprotective activities possibly due to the synergistic effects of higher amounts of chlorophyll a and other bioactive substances in the extract, revealing a $90 \%$ protection of the growth of mouse neuronal cells and a great reduction in Reactive Oxygen Species (ROS) production.
\end{abstract}

Keywords: Spirulina maxima; chlorophyll a; optimization; neuroprotective activities

\section{Introduction}

The blue-green algae Spirulina has been consumed since ancient times as a perfect food of the earth and has been frequently studied for many purposes, including as a food supplement, a functional food medicine, for cosmetics, and for many other biomaterials [1-5]. However, for most applications, it is considered more economical to use dried Spirulina itself rather than extract the biologically active components, such as phycocyanin, xanthophyll, chlorophylls, etc. because their extraction processes are difficult and they are extremely unstable in the presence of light, extreme temperatures, extraction solvents, etc. [6,7]. That is why it is mostly the powder of Spirulina that has been consumed, not extract forms, even though its taste is not palatable. Among the many bioactive substances that exist in Spirulina, the extracts of phycocyanin and xanthophyll are relatively well studied since they are unique components in Spirulina and are proven to have various useful biological functions including anticancer and anti-inflammation activities, as natural dyes, etc. [2-4]. However, the extraction of chlorophylls from Spirulina has not been studied much, even though Spirulina is also known to have very high amounts of chlorophylls, especially chlorophyll a, because there are many other resources with more natural chlorophylls [6-10]. Specifically, the need for natural chlorophyll a has been greatly increased because of its biological activities such as high antioxidant, anti-obesity, anti-cancer and anti-aging, etc. [1-4]. However, to obtain pure chlorophyll a from natural resources has not been easy since its purification steps are more complicated and also require special attention to avoid heat and light damage, etc. during the purification process [11,12]. That is why the cost of natural chlorophyll a is 
very high and has sharply increased compared to other chlorophylls such as chlorophyll b and c, etc. Therefore, Spirulina is an economical bioresource of good-quality natural chlorophyll a since most of the chlorophylls in Spirulina exist in the form of chlorophyll a, unlike most plants that have mixtures of chlorophyll $\mathrm{a}$ and $\mathrm{b}[11,12]$. However, the chlorophylls are very unstable and difficult to extract in intact forms out of the hard cells of Spirulina, which leads to very low extraction yields [13]. So far, the studies on chlorophyll extraction from Spirulina have focused mainly on extracting the chlorophylls through the supercritical extraction process with different combinations of various parameters such as solvent ratio, temperature, pressure, etc. There were also several reports on obtaining fair amounts of chlorophylls from plant resources by optimizing those variables [14,15]. However, most of the optimal conditions were at relatively high temperatures of $60-80^{\circ} \mathrm{C}$, which would cause a severe reduction in efficacy due to low contents of intact chlorophylls in the extracts. In addition to these difficulties, most extraction solvents, such as acetone, methanol, ether, etc., of the optimized extraction processes in the reports are not edible but were used since they are proven to be more efficient in extracting the chlorophylls than ethanol. However, the use of those inedible solvents would also cause a restriction in applications for the food industry [16].

Ultrasonic extraction has most often been used to break down cell walls with high efficiency, but without additional heat that could deteriorate heat-labile bioactive substances in the biomass [7,17-19] because a high frequency of ultrasonic vibration with high power input will make many cavitation bubbles in an extraction solvent, and the shock waves and liquid jets generated by breaking the bubbles near the cell walls could effectively destruct hard cell membranes in a shorter time $[19,20]$. However, there are still several hurdles to employing ultrasonic extraction processes in industrial applications such as relatively large equipment and more process controls as well as the difficulties of continuously combining with other processes such as fermentation and heating processes, etc. [21]. Therefore, in this work, a more realistic extraction process that uses ethanol, an edible solvent, will be optimized at a relatively low temperature by employing a simple ultrasonification process, not combined with other processes, which will minimally break down the structure and efficacy of the chlorophyll. Moreover, unlike most other works on the optimization of extraction processes, this study not only determines the optimal conditions but also evaluates the new or better biological functions of the extracts from the optimized process by comparing with the extract from a conventional extraction process. Specifically, in this work, the neuroprotective effects of the extracts from an optimized process will be further studied since chlorophyll a is known to have strong antioxidant activities that could be related to neuroprotective activities [7,17], even though the exact correlation is not yet well understood.

\section{Materials and Methods}

\subsection{Materials and Extraction of the Samples}

Dried marine Spirulina maxima was provided by the Korea Institute of Oceanology Science and Technology (KIOST, Jeju Research Center, Korea). A conventional ethanol extraction process was used for the control; $100 \mathrm{~g}$ of $S$. maxima powder was extracted with $1 \mathrm{~L}$ of $70 \%$ ethanol at $80{ }^{\circ} \mathrm{C}$ for $24 \mathrm{~h}$ with a reflux condensing extractor. For the ultrasonic extraction, $100 \mathrm{~g}$ of dried powder was added to $1 \mathrm{~L}$ of $70 \%$ ethanol in an ultrasonic extractor (AUG-R3-900, ASIA ULTRASONIC, Bucheon, Korea) that was equipped with a multi-controlled oscillator for variable frequency and a transducer at the bottom of the extractor and a circulating water bath for maintaining constant temperature within the extracting vessel. The ultrasonic extractor was operated under the conditions of $20-100 \mathrm{kHz}$ frequency at $120 \mathrm{~W} / \mathrm{cm}^{2}$ of fixed power input by a power generator inside the extractor, a temperature of $30-70{ }^{\circ} \mathrm{C}$ and $1-5 \mathrm{~h}$ for the extraction times. The ranges of these parameters were determined from previous experiments. Then, the extracts were filtered by a membrane filter paper and concentrated by a rotary vacuum evaporator (N-N series, Eyela, Tokyo, Japan). After that, the concentrated liquid was freeze-dried as a powder and stored at $-4{ }^{\circ} \mathrm{C}$ before the experiments. 


\subsection{Experimental Design}

The optimization of chlorophyll a $(\mathrm{Y})$ extraction was performed by the Response Surface Methodology (RSM). In Table 1, coded and uncoded values of the three independent variables, extraction time $\left(X_{1}, 1-5 \mathrm{~h}\right)$, temperature $\left(\mathrm{X}_{2}, 30-70{ }^{\circ} \mathrm{C}\right)$ and ultrasonic frequency $\left(\mathrm{X}_{3}, 20-100 \mathrm{kHz}\right)$, were defined by Central Composite Design (CCD) at five levels with 20 experimental runs with three replicates.

Table 1. Estimation of chlorophyll a contents in the extracts by the central composite experimental design for response surface analysis.

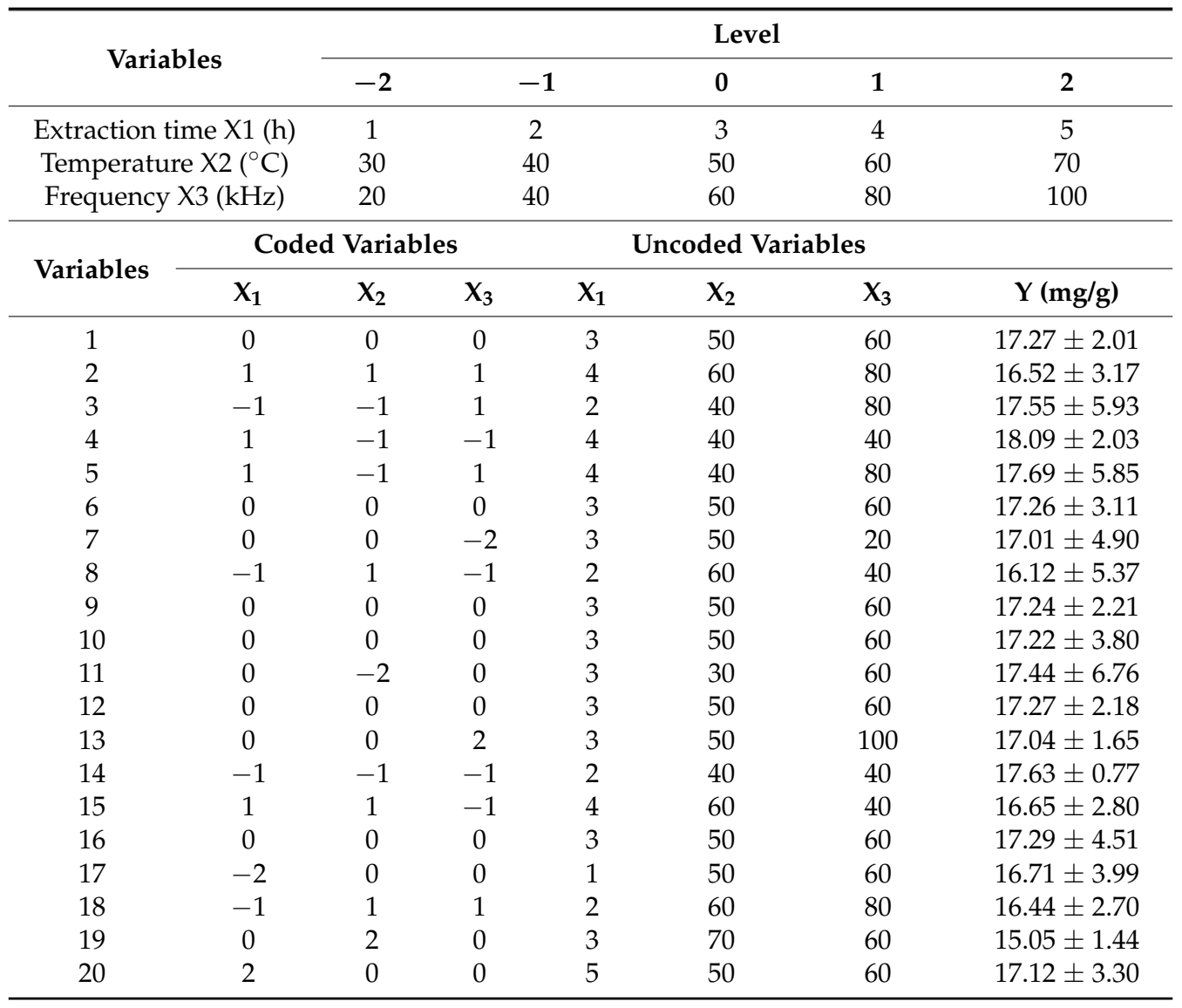

A mathematical model corresponding to the design is as follows:

$$
\mathrm{Y}=\beta_{0}+\sum_{i=1}^{k} \beta_{i} \mathrm{X}_{i}+\sum_{i=1}^{k} \beta_{i i} \mathrm{X}_{i}^{2}+\sum_{i=1}^{k-1} \beta_{i j} \mathrm{X}_{i} \mathrm{X}_{j}
$$

where $\mathrm{Y}$ is an independent variable of the chlorophyll a contents in the extracts, $\beta_{0}$ is the constant coefficient, $\beta_{i}$ is the linear coefficient for the main effect, $\beta_{i i}$ is the quadratic coefficient, and $\beta_{i j}$ is the interaction coefficient. The adequacies of the quadratic model were evaluated by the values of R2 between the experimental and predicted data. Various biological effects of the extracts from the optimized and conventional extraction conditions were further compared to reconfirm the validity of the experimental model [22].

\subsection{Measurement of the Contents of Chlorophylls a in the Extracts}

To estimate amounts of chlorophyll a in the extracts, High-Pressure Liquid Chromatography (HPLC, 500 Series, BIO-TEK, Winooski, VT, USA) was employed with C18 column (Jupiter C18 column, $4.6 \times 250 \mathrm{~mm}, 5 \mathrm{um}, 300 \mathrm{~A}, 00 \mathrm{G}-4053-\mathrm{E} 0$, Phenomenex, Torrance, CA, USA) under the following 
conditions: Acetonitrile : Methanol : Ethyl Acetate (6:2:2) as a mobile phase with isocratic condition at $1 \mathrm{~mL} / \mathrm{min}$ of flow rate for $20 \mathrm{~min}$, and then measured at $420 \mathrm{~nm}$ with a UV detector (BIO-TECK) by comparing with a standard of chlorophyll a (CAS\#479-61, Research Chemicals, Toronto, ON, Canada) [23].

\subsection{Antioxidant and Neuroprotective Activities of the Extracts}

To measure the antioxidant activities of the extracts, the $\alpha, \alpha$-diphenyl- $\beta$-picrylhydrazyl (DPPH) free radical scavenging activity was employed by using the Dietz method [24]: After mixing $150 \mu \mathrm{L}$ of $0.1 \mathrm{mM}$ DPPH solution prepared with methanol as the solvent and $150 \mu \mathrm{L}$ of the extract solution containing $100 \mu \mathrm{g} / \mathrm{mL}$ of the freeze-dried powder of the extract from each extraction process, the mixture was wrapped in foil to block light and left unattended for $30 \mathrm{~min}$ at room temperature. Thereafter, the optical density was measured at a wavelength of $517 \mathrm{~nm}$ by a microplate reader (Thermo Fisher Scientific, Waltham, MA, USA). The relevant values were estimated as DPPH radical scavenging activity (\%). The Reactive Oxygen Species (ROS) contents of glutamate-induced mouse hippocampal neuronal cell line (HT22, ATCC, Manassas, VA, USA) were measured by the following method [25]: First, HT22 cells were plated on a 48-well plate at $4.0 \times 10^{3}$ cells/well and incubated at $37^{\circ} \mathrm{C}$ for $24 \mathrm{~h}$. Then, $1 \mu \mathrm{L}$ of trolox, as a positive control, and $10 \mu \mathrm{L}$ of glutamate were added. After that, $200 \mu \mathrm{L}$ of the extract solution containing $100 \mu \mathrm{g} / \mathrm{mL}$ of the freeze-dried powder of the extract from each extraction process was added to a 96-well plate and further incubated in a $\mathrm{CO}_{2}$ incubator for $8 \mathrm{~h}$. After that, $10 \mu \mathrm{M}$ of $2^{\prime}, 7^{\prime}$-dichlorofluorescin diacetate (DCF-DA) was added to each well, and after $1 \mathrm{~h}$ of incubation, $1 \%$ Triton X-100 was also added to each well, and the absorbance of the solution was measured at the wavelengths of 488 and $530 \mathrm{~nm}$. The neuroprotective activities of the extracts were observed by using 3-(4,5-dimethythiazo-2-yl)-2,5-dipheny-tetrazoliumbromide (MTT) assay method [25] as follows: HT22 cells were plated on a 96-well plate at $1.5 \times 10^{4}$ cells/well and cultivated in a $\mathrm{CO}_{2}$ incubator for $24 \mathrm{~h}$. Then, either $10 \mu \mathrm{L}$ of glutamate or no treatment was added to the plates for either glutamate-induced effects or control, respectively. After that, $200 \mu \mathrm{L}$ of the extract solution containing $100 \mu \mathrm{g} / \mathrm{mL}$ of the freeze-dried powder of the extract from each extraction process were added to a 96-well plate and further incubated in a $\mathrm{CO}_{2}$ incubator for $24 \mathrm{~h}$. After the cultivation, $5 \mu \mathrm{g} / \mathrm{mL}$ of MTT solution were added into each 96-well plate and allowed to react for $4 \mathrm{~h}$. After the reaction, the supernatant in each well plate was removed, and $10 \mu \mathrm{L}$ of acid-isopropanol $(0.04 \mathrm{~N} \mathrm{HCl}$ in isopropanol) were added to the well plate. The absorbance of the solution in a 96-well plate was measured by a microplate ELISA reader (Tecan, St. Louis, MO, USA) at $565 \mathrm{~nm}$. Then, the ratio of final viable cell concentrations between non-treated cells as a control and glutamate-treated cells along with the addition of various concentrations of the extracts was expressed as Relative protection (\%) in the data.

\subsection{Statistical Analysis}

All experiments were performed three times and expressed as the mean \pm SD. Data were analyzed by the generalized linear model (GLM) procedure of the Statistical Analysis System (SAS, version 9.1, SAS Institute, Cary, NC, USA, 2004). The data were also analyzed by the one-way Analysis of Variance (ANOVA) test, and the mean values were considered significantly different at $p<0.05$.

\section{Results and Discussion}

The contents of chlorophyll a $(\mathrm{Y})$ for each experiment were estimated under the various extraction conditions designed by the CCD (Table 1).

In general, the amounts of chlorophyll a were increased the most by an increase in the frequency, followed by the process time; however, there was not much effect for an increase in the extraction temperature, possibly due to the destruction of the chlorophyll at higher temperatures. The highest chlorophyll a content, $18.09(\mathrm{mg} / \mathrm{g})$, was obtained for the extraction at $40 \mathrm{kHz}$ and $40{ }^{\circ} \mathrm{C}$ for $4 \mathrm{~h}$, and this value was much higher than $13.81(\mathrm{mg} / \mathrm{g})$ from a most conventional extraction process such 
as $70 \%$ ethanol at $80^{\circ} \mathrm{C}$ for $24 \mathrm{~h}$ (data not shown). This concentration was also found to be higher than those reported from conventional extractions from Spirulina and even other plants [26,27]. This result strongly implies that the optimized ultrasonification extraction is an effective process for extracting chlorophyll a from natural resources, and the optimized conditions of this method can be expected to yield high amounts of intact chlorophyll.

Tables 2 and 3 show the results of the ANOVA analysis and the RSM model, using the following equation:

$$
\begin{gathered}
Y=13.749+0.8014 X_{1}+0.1448 X_{2}+0.0041 X_{3}-0.0653 X_{1}^{2}-0.0023 X_{2}^{2}-0.0001 X_{3}^{2} \\
+0.0001 X_{1} X_{2}-0.0048 X_{1} X_{3}+0.0004 X_{2} X_{3}
\end{gathered}
$$

where, the regression coefficient (R2) was 0.969 , which indicates that this model is a good fit. The linear, quadratic and total model regressions were also highly significant $(p<0.001)$, except for the cross products such as $\mathrm{X}_{1} \mathrm{X}_{2}(p<0.01), \mathrm{X}_{1} \mathrm{X}_{3}(p<0.01)$ and $\mathrm{X}_{2} \mathrm{X}_{3}(p<0.05)$.

Table 2. Analysis of variance for chlorophyll a contents in the extracts of marine Spirulina maxima.

\begin{tabular}{cccc}
\hline Factor $^{1}$ & DF $^{2}$ & Sum of Squares & F-Value \\
\hline$X_{1}$ & 4 & 0.323 & 0.15 \\
$X_{2}$ & 4 & 7.6606 & $45.96^{* * * 3}$ \\
$X_{3}$ & 4 & 0.055 & $0.02^{*}$ \\
\hline
\end{tabular}

${ }^{1} \mathrm{X}_{1}$ : Process time $(\mathrm{h}), \mathrm{X}_{2}$ : Temperature $\left({ }^{\circ} \mathrm{C}\right), \mathrm{X}_{3}$ : Frequency $(\mathrm{kHz}) ;{ }^{2} \mathrm{DF}$ : degrees of freedom; ${ }^{3, *}$ Significant at $p<0.05,{ }^{* * *}$ Significant at $p<0.001$.

Table 3. The estimation of regression coefficients of the second-order polynomials for chlorophyll contents in the extracts.

\begin{tabular}{ccccc}
\hline Parameter $^{\mathbf{1}}$ & $\mathbf{D F}^{\mathbf{2}}$ & Coefficient & $\boldsymbol{t}$-Value & $\boldsymbol{p}$-Value \\
\hline Intercept & 1 & 13.749 & 8.348 & 0 \\
$\mathrm{X}_{1}$ & 1 & 0.8014 & 2.087 & 0.063 \\
$\mathrm{X}_{2}$ & 1 & 0.1448 & 3.603 & 0.005 \\
$\mathrm{X}_{3}$ & 1 & 0.0041 & 0.215 & 0.834 \\
$\mathrm{X}_{1} \mathrm{X}_{1}$ & 1 & -0.0653 & -2.045 & 0.068 \\
$\mathrm{X}_{2} \mathrm{X}_{2}$ & 1 & 0.0023 & -7.286 & 0 \\
$\mathrm{X}_{3} \mathrm{X}_{3}$ & 1 & -0.0001 & -1.184 & 0.264 \\
$\mathrm{X}_{1} \mathrm{X}_{2}$ & 1 & 0.0001 & 0.022 & 0.983 \\
$\mathrm{X}_{1} \mathrm{X}_{3}$ & 1 & -0.0048 & -1.699 & 0.12 \\
$\mathrm{X}_{2} \mathrm{X}_{3}$ & 1 & 0.0004 & 1.478 & 0.17 \\
\hline \multicolumn{5}{c}{$R^{2}=0.969$} \\
${ }^{1} \mathrm{X}_{1}$ : Process time (h), $\mathrm{X}_{2}:$ Temperature $\left({ }^{\circ} \mathrm{C}\right), \mathrm{X}_{3}$ : Frequency $(\mathrm{kHz}) ;{ }^{2} \mathrm{DF}:$ degrees of freedom.
\end{tabular}

Figure 1 also illustrates the three-dimensional response surfaces and contour plots for the chlorophyll a contents as a function of ultrasonic frequency, temperature and extraction time. As already demonstrated in Table 1, the amount of chlorophyll a in the extracts was most significantly increased with an increase in the frequency in the range of 20 to $40 \mathrm{kHz}$, and chlorophyll a also increased with an increase in the process time from 3 to $5 \mathrm{~h}$, while chlorophyll a was less significantly increased with the increase of the temperature from 30 to $40^{\circ} \mathrm{C}$. This could be caused by the breakdown of the chlorophylls in Spirulina at higher temperatures since chlorophylls are known to be heat sensitive and similar data were also reported [28]. In contrast, the results clearly proved that ultrasonification is very effective in extracting heat labile components, requiring a lower process temperature and shorter process time. Similar results were also found elsewhere [28,29]. 
(a)
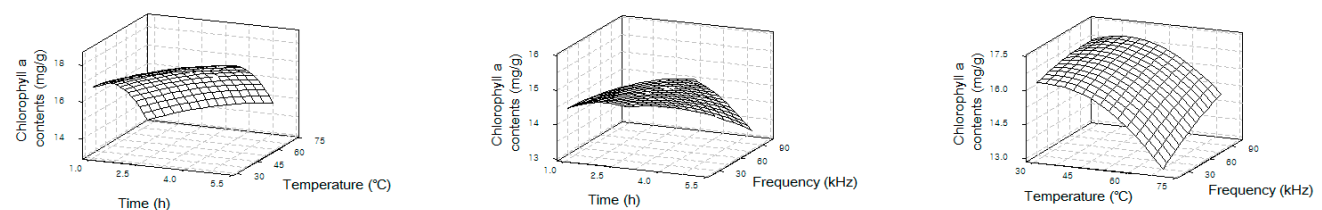

(b)
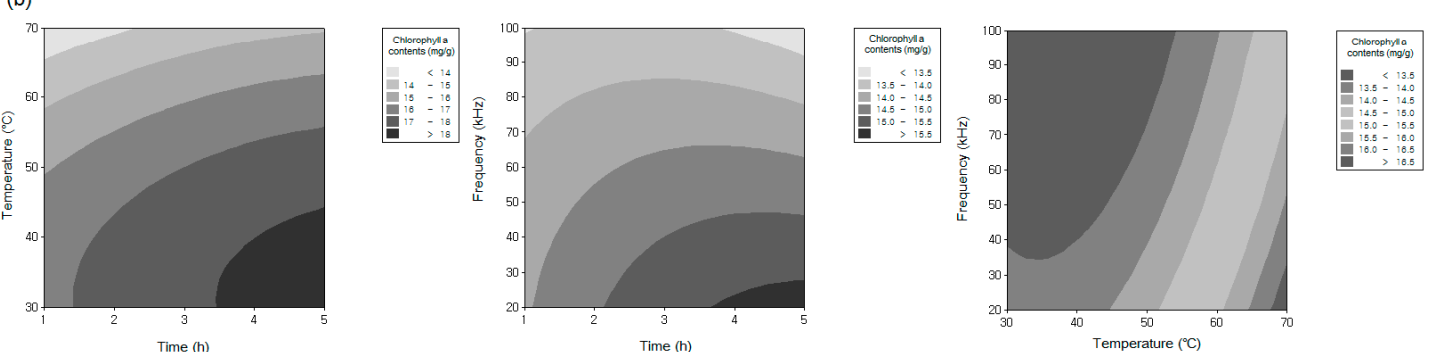

Figure 1. 3D response surfaces (a) and contour plots (b) as a function of ultrasonic frequency, temperature, and process time.

To evaluate the predictive model, Table 4 shows the results of the determination of an optimal extraction condition by the ridge analysis (Minitab release 14.12.1, Minitab Inc., State College, PA, USA, 2004) compared with the values from the model with the experimental data. Under an optimal condition, 18.21 (mg/g) of maximum chlorophyll a contents was expected, and actually, from the experiment under the same extraction conditions, $17.98 \pm 2.02(\mathrm{mg} / \mathrm{g})$ of chlorophyll a was measured, which indicates that the proposed model was well designed. The predicted concentration of the chlorophyll a from the optimized conditions was higher than all other concentrations obtained from 20 experiments in Table 1, which indicated that the optimization of the ultrasonic extraction seemed to be adequate and efficient in terms of yielding the highest chlorophyll a with a low input frequency, shorter process time, and low temperature. This highest content was also found to be even higher than other reported values from methanol and acetone extraction processes, etc. [12,30]. The final concentration of chlorophyll a estimated from an optimized process, $18.21(\mathrm{mg} / \mathrm{g})$, can also be compared with $13.18(\mathrm{mg} / \mathrm{g})$ from conventional ethanol extraction in terms of its productivity such as $3.72 \mathrm{vs.} 0.55(\mathrm{mg} / \mathrm{g} / \mathrm{h})$, respectively, since the extraction time of this process was much shorter than that of conventional extraction ( 4.91 vs. $24 \mathrm{~h}$ ). This productivity was also higher than those from other experimental results in Table 1. Moreover, in comparing the final concentrations obtained from a conventional ethanol extraction and experimental extraction conditions in Table 1, the increase of chlorophyll a production through this optimized process must be greatly advantageous, increasing the purification yield and its biological activities as well as reducing the production costs since pure chlorophyll a is one of the most expensive natural substances and is difficult to purify with its intact forms $[11,12]$.

Table 4. Predicted and experimented values of response variables processed under an optimal extraction condition.

\begin{tabular}{ccccc}
\hline & \multicolumn{2}{c}{ Dependent Variables } & \multicolumn{2}{c}{ Response Variables } \\
\hline \multirow{2}{*}{ Time (h) } & Temperature $\left({ }^{\circ} \mathbf{C}\right)$ & Frequency $(\mathbf{k H z})$ & $\begin{array}{c}\text { Predicted Value } \\
(\mathbf{m g} / \mathbf{g})\end{array}$ & $\begin{array}{c}\text { Experimental Value } \\
(\mathbf{m g} / \mathbf{g})\end{array}$ \\
\hline 4.91 & 32.59 & 20.52 & 18.21 & $17.98 \pm 2.02$ \\
\hline
\end{tabular}

As also shown in Figure 2, HPLC chromatograms confirmed that the extracts from the optimal process had a higher quality of chlorophyll a and other biologically active substances by comparing Figure $2 b, c$ with the standard chlorophyll a in Figure 2a. We believe that these results confirm that the proposed extraction conditions can be used to extract good amounts of intact chlorophyll a from 
Spirulina by a simple ultrasonification process. Therefore, this process can be employed to have more highly purified but less expensive chlorophyll a than from the conventional extraction process, which gives low chlorophyll a extraction yields [11,12]. In addition to the extraction of high amounts of chlorophyll a from Spirulina, the efficacy of the extracts should also be considered to re-confirm the optimal extraction conditions, a result that could be used to expand the utilization of the extracts.

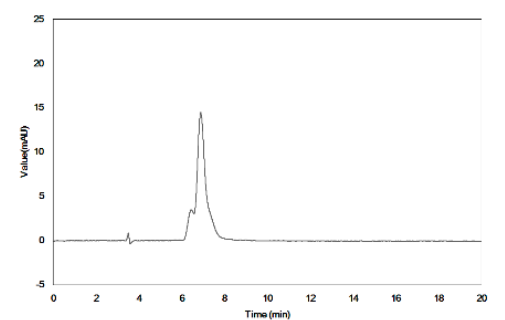

(a)

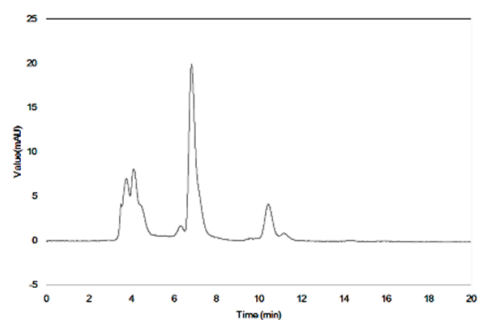

(b)

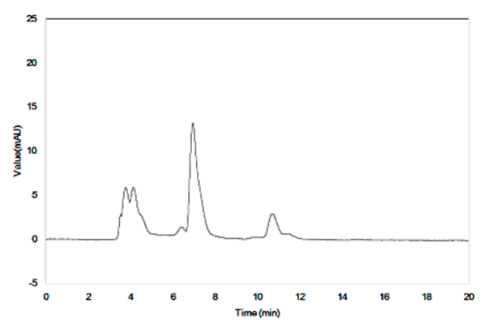

(c)

Figure 2. Comparison of High-Pressure Liquid Chromatography (HPLC) analysis of chlorophyll a contents by different extraction conditions. (a) Standard (chlorophyll a); (b) optimal extraction conditions; (c) conventional extraction conditions.

First, Figure 3 demonstrates that higher amounts of chlorophyll a reflect better neuroprotective activities of the extract from optimal extraction conditions than from a conventional ethanol extraction at high temperature and with a long process time. In particular, the extract from the optimal conditions enhanced the growth of the glutamate-induced mouse hippocampal neuronal cell line compared to that from a conventional ethanol process: $90.71 \pm 2.13 \%$ vs. $73.01 \pm 0.03 \%$ of the cell growth protection for the control with the addition of $100(\mu \mathrm{g} / \mathrm{mL})$ of the extracts.

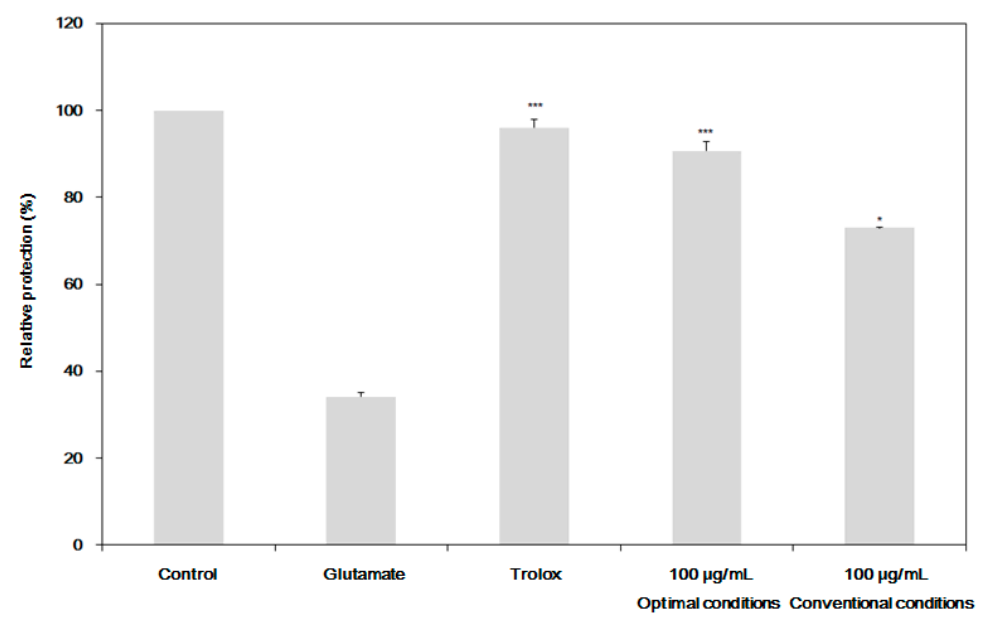

Figure 3. Comparison of the neuroprotective activities of the extracts from the optimal extraction process and a conventional $70 \%$ ethanol extraction process by the growth of the glutamate-induced mouse hippocampal neuronal cell line (HT22). * Significant at $p<0.05,{ }^{* * *}$ Significant at $p<0.001$.

As shown in Figure 4, the extract from the optimal conditions also greatly reduced the production of Reactive Oxygen Species (ROS) from the glutamate-induced mouse hippocampal neuronal cells compared to the same amount of the extract from a conventional ethanol extraction because the increase of ROS production is very closely related to oxidative stress within the cells and also indicates the lowest neuroprotective activity [31,32]. These neuroprotective activities were found to be better than those of other natural resources such as Aronia melanocarpa and Codonopsis lanceolata [31,32]. 


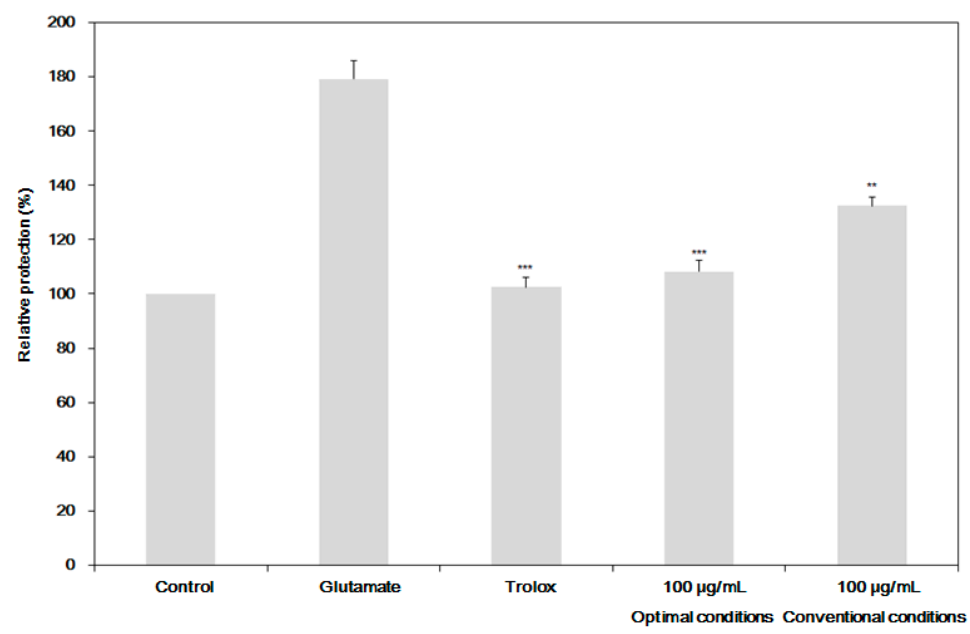

Figure 4. The reduction in Reactive Oxygen Species (ROS) production from the glutamate-induced mouse hippocampal neuronal cell line (HT22) by the addition of $100(\mu \mathrm{g} / \mathrm{mL})$ of the extracts from the optimal extraction conditions and a conventional extraction process. ${ }^{* *}$ Significant at $p<0.01$, *** Significant at $p<0.001$.

Figure 5 compares the antioxidant activities of the extracts from a conventional extraction condition, $70 \%$ ethanol at $8{ }^{\circ} \mathrm{C}$ for $24 \mathrm{~h}$, and the extract from the optimal conditions of the proposed model. Figure 4 clearly illustrates that the extract from the optimal conditions had higher DPPH radical scavenging activities than that from a conventional process, $69.38 \pm 4.13 \%$ vs. $58.25 \pm 5.23 \%$, respectively. Higher biological activities shown in Figures $3-5$ could be attributed by synergistic effects of higher amounts of chlorophyll a and also other bioactive substances in the extract from the optimal condition since this extract contained more biologically active substances than the extract from the conventional process, as already shown in Figure 2. More detailed studies on the effects of chlorophyll a on the neuroprotective activities of the extracts should be undertaken. However, in general this result would suggest that $S$. maxima extract from proper extraction conditions is a promising candidate for a functional food to prevent memory impairment and related diseases by enhancing neuroprotective activities through an optimal extraction processes due to the high concentrations of chlorophylls and other bioactive components in the optimized extract.

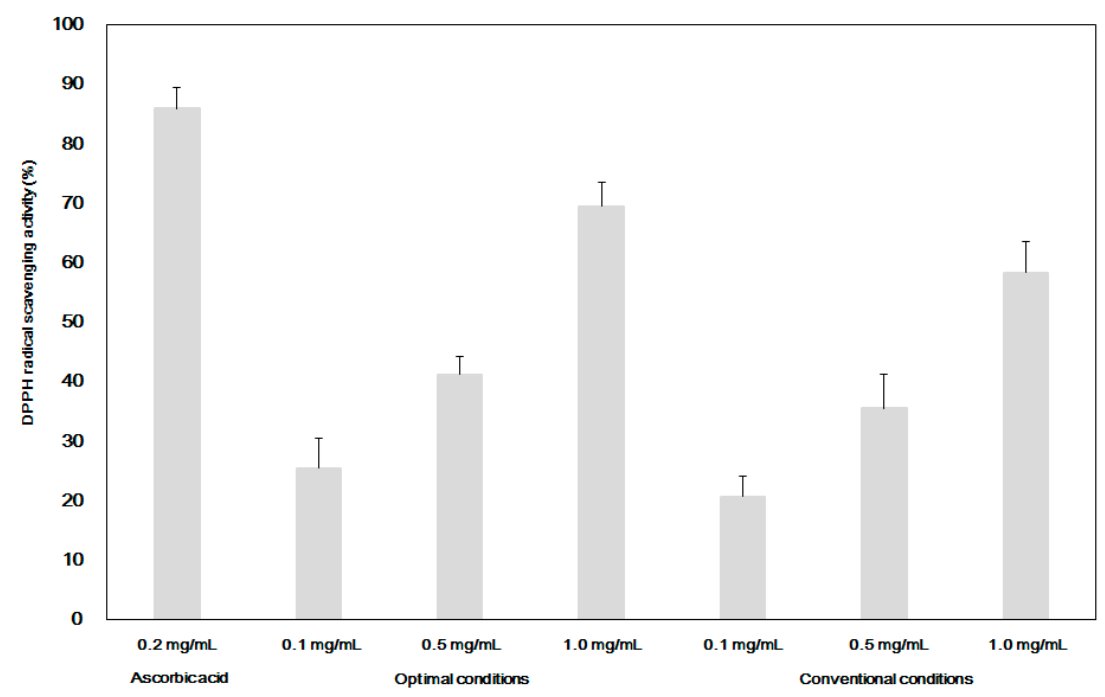

Figure 5. The $\alpha$, $\alpha$-diphenyl- $\beta$-picrylhydrazyl (DPPH) radical scavenging activity of the extracts from the optimal extraction conditions and a conventional extraction process. 


\section{Conclusions}

In this work, it was first shown that the optimization of a simple ultrasonic extraction process can obtain high amounts of heat-labile chlorophyll a from the marine alga Spirulina maxima by combining with input frequency, process time and temperature, etc., which has not been considered much compared with other extraction conditions. This work proved that the ultrasonic frequency and process time are more important for chlorophyll a extraction than the process temperature, as much of the chlorophyll a would also be degraded at high temperature. It can also be expected that the optimized process helps to reduce purification steps to obtain pure chlorophyll a since most of the chlorophylls in the extracts existed in the form of chlorophyll a. It was also first reported that the optimization of extraction variables can not only result in the extraction of high yield but also can maintain the high efficacy of the extracts with high concentrations of intact chlorophyll a and other biologically active substances. This hypothesis was confirmed by showing the higher neuroprotective activities of the extracts from the optimized extraction condition. Therefore, we can see that Spirulina extract from an optimal condition with high concentrations of chlorophyll a can be developed as a functional food for preventing memory impairment and related diseases, and also possibly employed for processing other heat-sensitive bioactive substances from natural resources.

Author Contributions: Woo Yong Choi carried out all of the experiments and Hyeon Yong Lee designed the whole experiments and drafted the manuscript. All authors read and approved the final manuscript.

Conflicts of Interest: The authors declare no conflict of interest.

\section{References}

1. Wells, M.L.; Potin, P.; Craigie, J.S.; Raven, J.A.; Merchant, S.S.; Helliwell, K.E.; Smith, A.G.; Camire, M.E.; Brawley, S.H. Algae as nutritional and functional food sources: Revisiting our understanding. J. Appl. Phycol. 2017, 29, 949-982. [CrossRef] [PubMed]

2. Hernadez, A.C.; Nieves, I.; Meckes, M.; Chamorro, G.; Barron, B.L. Antiviral activity of Spirulina maxima against herpes simplex virus type 2. Antivir. Res. 2002, 56, 279-285. [CrossRef]

3. García, J.L.; Vicente, M.; Galán, B. Microalgae, old sustainable food and fashion nutraceuticals. Microb. Biotechnol. 2017, 10, 1017-1024. [CrossRef] [PubMed]

4. Clark, J.G.; Kostal, K.M.; Marino, B.A. Modulation of collagen production following bleomycin-induced pulmonary fibrosis in hamsters. Presence of a factor in lung that increases fibroblast prostaglandin E2 and cAMP and suppresses fibroblast proliferation and collagen production. J. Biol. Chem. 1982, 257, 8098-8105. [PubMed]

5. Morias, M.G.; Costa, J.A.V. Biofixation of carbon dioxide by Spirulina sp. and Scenedesmus obliquus cultivated in a three-stage serial tubular photobioreactor. J. Biotechnol. 2007, 129, 439-445. [CrossRef] [PubMed]

6. Lee, Y.J.; Kim, S.H.; Kim, J.S.; Han, J.A.; Seo, H.J.; Lim, H.J.; Choi, S.Y. Studies on simultaneous determination of chlorophyll a and b, pheophorbide a, and $\beta$-carotene in Chlorella and Spirulina products. J. Food Hyg. Saf. 2005, 20, 141-146.

7. Yamada, T.; Sakaguchi, K. Comparative studies on Chlorella cell walls: Induction of protoplast formation. Arch. Microbiol. 1982, 132, 10-13. [CrossRef]

8. Rudolph, C. The therapeutic value of chlorophyll. Clin. Podiatr. Med. Surg. 1930, 37, 119-121.

9. Vogel, J.; Jonker-Termont, D.S.; Lieshout, E.M.; Katan, M.B.; Meer, R. Green vegetables, red meat and colon cancer: Chlorophyll prevents the cytotoxic and hyperproliferative effects of haem in rat colon. Carcinogenesis 2005, 26, 387-393. [CrossRef] [PubMed]

10. Mccarty, M.F. The chlorophyll metabolite phytanic acid is a natural rexinoid-Potential for treatment and prevention of diabetes. Med. Hypotheses 2001, 56, 217-219. [CrossRef] [PubMed]

11. Danesi, E.D.G.; Rangel-Yagui, C.O.; Carvalho, J.C.M.; Sato, S. Effect of reducing the light intensity on the growth and production of chlorophyll by Spirulina platensis. Biomass Bioenergy 2004, 26, 329-335. [CrossRef]

12. Bhat, S.R. Chlorophyll: The wonder pigment. Sci. Rep. 2005, 42, 29-32.

13. Hosikian, A.; Lim, S.; Halim, R.; Danquah, M.K. Chlorophyll extraction from microalgae: A review on the process engineering aspects. Int. J. Chem. Eng. 2010, 2010, 1-11. [CrossRef] 
14. Kong, W.; Liu, N.; Zhang, J.; Yang, Q.; Hao, S.; Song, H.; Xia, C. Optimization of ultrasound-assisted extraction parameters of chlorophyll from Chlorella vulgaris residue after lipid separation using response surface methodology. J. Food Sci. Technol. 2014, 51, 2006-2013. [CrossRef] [PubMed]

15. Lu, J.; Feng, X.; Han, Y.; Xue, C. Optimization of subcritical fluid extraction of carotenoids and chlorophyll a from Laminaria japonica Aresch by response surface methodology. J. Sci. Food Agric. 2014, 94, 139-145. [CrossRef] [PubMed]

16. Daniel, A.A.; Wendell, H.M. Extraction of total phenolic and flavonoids from edible wild and cultivated medicinal mushrooms as affected by different solvents. J. Nat. Prod. Plant Resour. 2013, 3, 37-42.

17. Zheng, H.; Yin, J.; Gao, Z.; Huang, H.; Ji, X.; Dou, C. Disruption of Chlorella vulgaris cells for the release of biodiesel-producing lipids: A comparison of grinding, ultrasonication, bead milling, enzymatic lysis, and microwaves. Appl. Biochem. Biotechnol. 2011, 164, 1215-1224. [CrossRef] [PubMed]

18. Ma, Y.Q.; Ye, X.Q.; Fang, Z.X.; Chen, J.C.; Xu, G.H.; Liu, D.H. Phenolic compounds and antioxidant activity of extracts from ultrasonic treatment of Satsuma Mandarin (Citrus unshiu Marc.) peels. J. Agric. Food Chem. 2008, 56, 5682-5690. [CrossRef] [PubMed]

19. Ince, A.E.; Sahin, S.; Sumnu, G. Comparison of microwave and ultrasound-assisted extraction techniques for leaching of phenolic compounds from nettle. J. Food Sci. Technol. 2014, 51, 2776-2782. [CrossRef] [PubMed]

20. Dranca, F.; Oroian, M. Optimization of ultrasound-assisted extraction of total monomeric anthocyanin (TMA) and total phenolic content (TPC) from eggplant (Solanum melongena L.) peel. Ultrason. Sonochem. 2016, 31, 637-646. [CrossRef] [PubMed]

21. Majid, I.; Nayik, G.A.; Nanda, V. Ultrasonication and food technology: A review. Food Sci. Technol. 2015, 1, 1-11. [CrossRef]

22. Kim, Y.H.; Kim, W.S.; Kim, J.M.; Choi, S.; Jung, T.D.; Lee, J.H.; Kim, J.D.; Lim, J.K.; Lee, O.H. Optimization of extraction conditions for mixture of Camellia sinensis L. and Artemisia argyi by response surface methodology. J. Food Hyg. Saf. 2016, 31, 278-285. [CrossRef]

23. Petrović, S.M.; Savić, S.R.; Marković, D.Z.; Petronijević, Ž.B. In vitro studies of temperature and pH influence on chlorophyll degradation by horseradish peroxidase: Spectroscopic and HPLC studies. Hem. Ind. 2014, 68, 233-239. [CrossRef]

24. Dietz, B.M.; Kang, Y.H.; Liu, G.; Eggler, A.L.; Yao, P.; Chadwick, L.R.; Pauli, G.F.; Farnsworth, N.R.; Mesecar, A.D.; Breeman, R.B.; et al. Xanthohumol isolated from Humulus lupulus inhibits menadione-induced DNA damage through induction of quinone reductase. Chem. Res. Toxicol. 2005, 18, 1296-1305. [CrossRef] [PubMed]

25. Lee, J.; Weon, J.B.; Ma, C.J. Neuroprotective activity of phytosterols isolated from Artemisia apiacea. Korean J. Pharmacogn. 2014, 45, 214-219.

26. Macias-Sanchez, M.D.; Mantell, C.; Rodríguez, M.; Ossa, E.M.; Lubián, L.M.; Montero, O. Comparison of supercritical fluid and ultrasound-assisted extraction of carotenoids and chlorophyll a from Dunaliella salina. Talanta 2009, 77, 948-952. [CrossRef] [PubMed]

27. Al-Hamani, S.; Burnett, C.; Durrant, G. Effect of low-dose ultrasonic treatment on Spirulina maxima. Aquac. Eng. 1998, 19, 17-28. [CrossRef]

28. Erge, H.S.; Karadeniz, F.; Koca, N.; Soyer, Y. Effect of heat treatment on chlorophyll degradation and color loss in green peas. Assoc. Food Technol. 2008, 33, 225-233.

29. Schwartz, S.J.; Elbe, J.H.V. Kinetics of chlorophyll degradation to pyropheophytin in vegetables. J. Food Sci. 1983, 48, 1303-1306. [CrossRef]

30. Lee, D.H.; Hong, J.H. Antioxidant activities of chlorella extracts and physicochemical characteristics of spray-dried Chlorella powders. Korean J. Food Preserv. 2015, 22, 591-597. [CrossRef]

31. Lee, H.Y.; Weon, J.B.; Ryu, G.; Yang, W.S.; Kim, N.Y.; Kim, M.K.; Ma, C.J. Neuroprotective effect of Aronia melanocarpa extract against glutamate-induced oxidative stress in HT22 cells. BMC Complement. Altern. Med. 2017, 17, 207-213. [CrossRef] [PubMed]

32. Weon, J.B.; Yun, B.R.; Lee, J.; Eom, M.R.; Ko, H.J.; Lee, H.Y.; Park, D.S.; Chung, H.C.; Chung, J.Y.; Ma, C.J. Neuroprotective effect of steamed and fermented Codonopsis lanceolata. Biomol. Ther. 2014, 22, 246-253. [CrossRef] [PubMed]

(C) 2017 by the authors. Licensee MDPI, Basel, Switzerland. This article is an open access article distributed under the terms and conditions of the Creative Commons Attribution (CC BY) license (http://creativecommons.org/licenses/by/4.0/). 